\title{
Evaluation of chemical compounds for induction of male sterility in wheat (Triticum aestivum $\mathbf{L}$.)
}

Kajal Chakraborty · C. Devakumar

(C) Springer Science + Business Media B.V. 2006

Erratum to: Euphytica (2006) 147: 329-335

DOI 10.1007/s10681-005-9025-z

Due to an unfortunate error, the first author's surname appeared incorrectly in the online version of the above mentioned article as:

\section{Kajal hakraborty}

where it should have read:

\section{Kajal Chakraborty}

The online version of the original article can be found at http://www.dx.doi.org/10.1007/s10681-005-9025-z

K. Chakraborty · C. Devakumar Division of Agricultural Chemicals, Indian Agricultural Research Institute (IARI), New Delhi-110012, India

K. Chakraborty $(\bowtie)$

Division of PNP, Central Marine Fisheries Research Institute, Ernakulam North P.O., P.B. No. 1603,

Cochin-682018, Kerala, India

e-mail: kajal_iari@yahoo.com 